\title{
Endovascular aortic repair of a thoracic aneurysm in a porcelain aorta
}

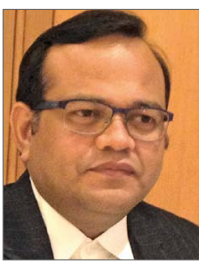

Rajesh Vijayvergiya ${ }^{1 *}$, DM; Sagar Makode ${ }^{1}$, DM; Ganesh Kasinadhuni ${ }^{1}$, DM;

Anupam Lal ${ }^{2}$, MD; Ajay Savlania ${ }^{3}$, MS; Prashant Panda ${ }^{1}, \mathrm{DM}$

1. Department of Cardiology, Post Graduate Institute of Medical Education \& Research, Chandigarh, India; 2. Radio-diagnosis, Post Graduate Institute of Medical Education \& Research, Chandigarh, India; 3. Vascular Surgery, Post Graduate Institute of Medical Education \& Research, Chandigarh, India

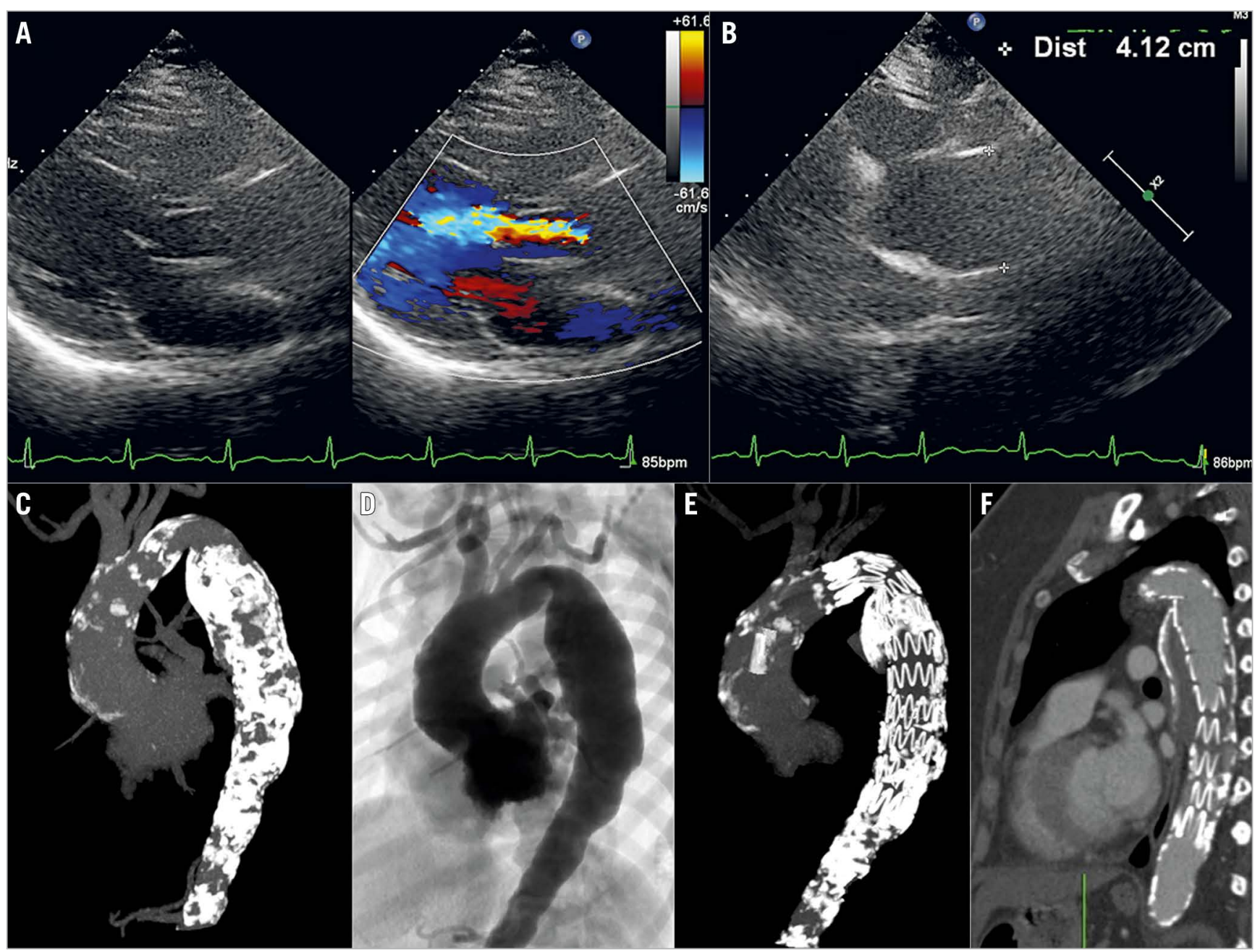

*Corresponding author: Department of Cardiology, Advanced Cardiac Centre, Post Graduate Institute of Medical Education \& Research, Sector 12, Chandigarh 160012,India.E-mail: rajeshvijay999@hotmail.com 
A 55-year-old diabetic, hypertensive female presented with dyspnoea on exertion (New York Heart Association [NYHA] Class II) for the last year. Clinical examination revealed a short, early diastolic murmur of aortic regurgitation (AR). Echocardiography revealed a normal, non-calcified tricuspid aortic valve having moderate AR, secondary to the dilated ascending aorta of size $41.2 \mathrm{~mm}$ (Panel A, Panel B). Computed tomography (CT) angiography revealed a severe, circumferentially calcified thoracoabdominal aorta, i.e., porcelain aorta (Panel C), with a fusiform thoracic aneurysm (Panel D). The aneurysm measured $48.5 \mathrm{~mm}$ in diameter, $154 \mathrm{~mm}$ in length, arising $20 \mathrm{~mm}$ distal to the left subclavian artery. The ascending aorta was also dilated with a maximum diameter of $42.7 \mathrm{~mm}$. The arch of the aorta and its branches were normal. Serum tests for autoimmune disease and inflammatory large cell arteritis were negative. Her serum creatinine was $0.72 \mathrm{mg} / \mathrm{dL}$. The likely aetiology of porcelain aorta was diabetesrelated atherosclerosis. After discussion in the Heart Team forum of our institute, percutaneous thoracic endovascular aortic repair
(TEVAR) was planned. A $30 \times 200 \mathrm{~mm}$ thoracic stent graft (Zenith $\mathrm{TX}^{\circledR}$ TAA Endovascular Graft; Cook Medical, Bloomington, IN, USA) was deployed distal to the origin of the left subclavian artery through the surgically exposed right femoral artery. There was no type 1 endoleak following the stent deployment. Her coronary angiography was normal without any significant narrowing. Post procedure, the femoral access site was repaired using a 5-0 polypropylene suture. She was discharged on aspirin, statins, oral hypoglycaemic agents and angiotensin receptor blockers for comorbid illness. Repeat CT angiography at three-month followup showed a well-apposed stent graft, and complete exclusion of the thoracic aneurysm without any endoleak (Panel E, Panel F). She was asymptomatic during the two years of follow-up, without any further progression of AR or dilatation of the ascending aorta as assessed by echocardiography.

\section{Conflict of interest statement}

The authors have no conflicts of interest to declare. 